\title{
Reflexões: os sentidos sociais da programação
}

\section{Elizabeth Bastos Duarte}

Doutora; Universidade Federal de Santa Maria

bebeth@terra.com.br

\begin{abstract}
Riassunto
O presente trabalho propõe desenvolver uma reflexão sobre o modo de funcionamento, além de lógicas e funções que presidem a organização das grades de programação das emissoras generalistas, examinando com especial atenção as transformações pelas quais vem passando a programação da Rede Globo de Televisão (RGT), com a finalidade expressa de levantar hipóteses, a serem confirmadas em pesquisa posterior, que possibilitem uma melhor compreensão dos sentidos e das razões que norteiam as alterações em curso. Nessa perspectiva, procura analisar os investimentos feitos pela emissora na produção ficcional, nos remakes e, principalmente, nos programas de auditório, visto que atualmente a RGT coloca no ar, semanalmente, mais de 12 programas, ligados a esse subgênero televisual. Os apontamentos finais procuram apresentar justificativas para essas alterações.
\end{abstract}

\section{Palavras-chave}

Grade de programação. Princípios de organização. Sentidos das alterações.

\section{Das considerações iniciais}

Os estudiosos dizem, e a gente repete, sem pejo ou maiores questionamentos, que a estruturação das grades de programação das emissoras de televisão comerciais generalistas vem procurando articular, ao longo do tempo, a oferta de produtos ao cotidiano de seu público alvo - os telespectadores. São, assim, as características e o ritmo de vida de uma dada sociedade os responsáveis, em última instância, pela escolha dos programas a serem veiculados e pela definição de seu horário de exibição. Dessa forma, as grades das diferentes emissoras correspondem a tentativas de administração não só do gosto, mas da 
temporalidade complexa e forçosamente direcionada da parcela de público disponível em cada faixa horária.

Em outros termos, existe, nos canais generalistas, uma justificável e assumida preocupação com a adequação entre o tipo de programa ofertado em um dado horário e o dia a dia do telespectador, até porque a presença e a distribuição das peças publicitárias obedecem a esse mesmo critério, uma vez que os anunciantes, responsáveis pela manutenção e lucratividade das empresas privadas de televisão, estão sempre atentos aos horários em que estão disponíveis os virtuais consumidores de seu negócio. Daí razão pela qual é preciso construir, conquistar e fidelizar uma audiência estável, com as mesmas características, semanalmente, para que a publicidade possa falar com um público específico e nele focar suas ações.

E, contrariamente ao que se poderia pensar, as grades foram se tornando, ao longo dos anos 2000, muito mais rígidas do que as de décadas passadas, talvez porque a fidelização do telespectador seja tão importante para que a emissora possa se responsabilizar por um determinado público frente aos anunciantes: experiências e propostas novas são sempre um risco que deve ser cuidadosamente avaliado. Assim, a programação, em princípio, não tem como objetivo prioritário colocar, na grade, em cada faixa horária, um novo programa, de alta qualidade e originalidade, direcionado a todos os públicos, mas um programa que atinja a maioria do público disponível naquele horário, e, importante, ao menor custo de realização possível.

Ora, a grade de programação da maior cadeia de televisão privada do país e referência para a organização das demais grandes redes brasileiras, a da Rede Globo de Televisão (RGT), vem passando por significativas alterações que, de certa forma, contrariam tanto essa rigidez antes apontada, como o próprio modelo por ela implementado, respeitado e reiterado no decorrer dos últimos cinquenta anos.

Cabe questionar, portanto, as razões que vêm levando a RGT a abdicar, ao menos parcialmente, de um modelo que sempre lhe foi tão caro e lucrativo, modelo esse que, ao longo dos anos, tem sido por ela tão insistentemente cultivado, contando com ampla aprovação dos telespectadores e da sociedade brasileira em geral. Afinal, essa grade passou a interferir até mesmo nos hábitos cotidianos dos brasileiros e em seus tempos sociais: ninguém sai de casa antes do Jornal Nacional; o futebol só começa após o término do capítulo da novela das nove; ninguém perde os últimos capítulos das novelas, ou os episódios de Tapas e Beijos, por exemplo. 
Assim, se essa programação sempre esteve em perfeita sintonia com os telespectadores, se tem sido organizada para eles - afinal, a televisão é um negócio -, tudo leva a crer que essas modificações traduzam profundas transformações nas expectativas, nas configurações sociais e nos hábitos dos consumidores brasileiros, bem como correspondam a alterações no gerenciamento dos interesses da empresa.

Diante do exposto, o presente trabalho propõe-se a refletir sobre o modo de funcionamento, sobre as lógicas e funções que vêm presidindo a organização das grades de programação das emissoras generalistas, examinando com especial atenção as transformações pelas quais está passando a programação da Rede Globo de Televisão, com a finalidade de levantar hipóteses, a serem confirmadas em pesquisas posteriores, que possibilitem uma melhor compreensão das razões e dos sentidos que norteiam as alterações em curso.

\section{Do modo de funcionamento das grades de programação: lógicas e funções}

A televisão, no contexto brasileiro, nasceu como empresa privada. Nessa perspectiva, trata-se de uma indústria de discursos que se rege pelas leis do mercado: as emissoras (canais abertos) sustentam-se com a venda de espaços comerciais, cujo valor é proporcional à audiência por elas obtida com os produtos que veiculam em um determinado horário.

Três instâncias têm voz ativa na seleção dos programas e na estruturação da grade de programação de uma emissora de televisão: a empresarial, que escolhe os programas tendo em vista o lucro, que, através de sua exibição, pode ser obtido, considerando a continuidade semântica entre programas e todo o tipo de promoção, essa última com interferência até mesmo no próprio conteúdo das narrativas; a institucional, que atua na compra ou produção/realização dos programas, tendo em vista as funções que a emissora se atribui; e, por fim, a da marca, que envolve as escolhas de programas alinhados com a imagem que a emissora visa projetar e/ou manter de si. Aliás, é nessa perspectiva, segundo Jost (2010, p. 91), que cada programa exibido é parte constitutiva da imagem da emissora e a imagem da emissora semantiza cada um dos programas exibidos. As escolhas dos programas não são, assim, inocentes: ocorrem a partir de uma minuciosa seleção de conteúdos, da cuidadosa definição das faixas horárias adequadas à sua exibição e da 
consideração ao entorno - sucessão ou aproximação de determinados produtos na grade de programação.

Dessa forma, a escolha, a feitura e a distribuição, na grade de programação, dos produtos televisuais estão integradas aos princípios que regem a produção das mercadorias em geral, de forma a torná-las capazes de despertar o interesse e conquistar o telespectador, contando, se possível, com a qualidade necessária para aprovação da crítica especializada: trata-se de um negócio que depende da audiência, em um mercado extremamente disputado.

Também em função do lucro, a programação e os próprios programas são organizados com vistas a reservar espaços para todo o tipo de mensagens promocionais de caráter comercial, social, autorreferencial, veiculadas tanto em espaços intervalares, como sob a forma de inserções no interior dos produtos.

O velho princípio, sempre reiterado na televisão comercial, da serialização, critério maior de distribuição, estruturação e fragmentação dos produtos televisuais, determina que os programas comportem, cada um deles, um certo número de emissões, apresentadas como segmentos componentes do texto maior, representado pelo todo do próprio programa. A serialização prevê que cada programa ocupe um determinado e reiterado espaço, de forma regular, na programação, ou seja, que conte com dia(s) predefinido(s) de apresentação semanal ou mensal; com o tempo de duração de cada emissão preestabelecido; e, se for possível, com a previsão do período total de permanência do programa na grade de programação da emissora. A adoção dessa lógica estrutural da serialidade, cabe enfatizar, é extensiva a toda a produção televisual - telejornais, programas de auditório, reportagens, entrevistas, reality shows, etc -, não se restringindo apenas à ficcional: o plano de realidade (metarrealidade, suprarrealidade, pararrealidade) com que opera preferencialmente um programa de televisão não interfere na sua seriação, pois a esse critério se submetem todos os produtos televisuais. Além disso, as emissões dos programas segmentam-se em blocos para dar conta dos intervalos publicitários previstos.

Assim, a serialidade diz respeito, primeiramente, a um tipo de organização que é exterior ao programa, referente aos princípios de seleção, distribuição e combinação de programas na grade das emissoras, que, atenta às diferentes lógicas e demandas econômicas, culturais e sociais, já referidas, considera: (1) as características do público disponível nos diferentes horários e dias da semana (sexo, faixa etária, nível cultural, condições intelectuais), com especial atenção àqueles que são obrigados a ficar em casa - 
mulheres, idosos, aposentados, desempregados, etc, e às suas atividades - escola, cursos, preparação de refeições, retorno para casa; (2) os gostos e preferências de cada público-alvo e os subgêneros de programas que mais agradam a audiência de cada horário; (3) as ofertas da concorrência no mesmo horário. Embora, atualmente, os hábitos de consumo estejam se alterando, uma vez que todos podem estar conectados à programação televisual em diferentes momentos do dia, via internet ou celular, tudo indica que a televisão continue partindo dessa homogeneização da audiência em cada faixa horária para organizar sua grade, sendo a inserção de um programa resultado de um minucioso estudo sobre a configuração do público disponível em cada faixa horária.

Ocorre que a serialização incide também sobre a estruturação interna dos programas; ela, aliada à adoção de um subgênero, interfere diretamente na construção das diversas emissões que compõem um programa, determinando: (1) a frequência de sua exibição; (2) o tipo de relação sintagmática que esses fragmentos do programa contraem entre si continuidade ou descontinuidade; (3) a decorrente forma de apresentação desses fragmentos - capítulos, episódios, apresentações, edições; (4) a consequente forma de estruturação narrativa desses fragmentos - autonomia ou dependência de sentido das emissões umas em relação às outras.

Assim, considerando os princípios da serialização e da segmentação das emissões por blocos, cada uma das emissões de um programa organiza sua narrativa utilizando-se, estrategicamente, dos tempos fortes, ou seja, fragmentando o relato em momentos em que a trama, construída com esse propósito, deve resolver impasses, deixando os telespectadores em suspense, à espera da sequência seguinte, com vistas a impedir a troca de canal, por medo de perder o desenrolar das tramas, ou, no caso dos telejornais, a notícia mais relevante do dia. 0 telespectador fica, segundo Jost (2010), cativo tanto pela promessa de que o que está por vir é melhor do que aquilo a que ele está assistindo, como pela curiosidade de conhecer os encaminhamentos, destaques e finais dos relatos.

A composição da grade de programação exige um detalhado planejamento, pois a disposição serial dos produtos televisuais, ao selecionar e combinar programas, opera com dois eixos temporais: o horizontal, que dá conta do desenvolvimento sintagmático dos programas, na sequencialidade semanal de suas emissões, incidindo sobre a programação enquanto periodicidade e reiteração; o vertical, que responde à inserção da emissão de um dado programa no fluxo da grade diária de uma emissora, em horário definido, precedido e sucedido por outros produtos. 
A duração total do tempo de permanência de um programa no ar, está, de certa forma, ligada ao subgênero: alguns programas têm o tempo total de exibição predeterminado. Existem, não obstante, outros tantos que permanecem na grade durante anos, sendo sua continuidade definida pela audiência. Esse é o caso dos telejornais, dos programas de reportagens, de alguns seriados ou programas de auditório, etc. Há, ainda, os produtos que vão ao ar por temporadas, novas edições e reapresentações.

As emissoras esforçam-se por combinar os eixos horizontal e vertical, exibindo uma programação fixa, que respeita horários e dias da semana, adaptando seus programas aos interesses dos anunciantes. A programação noturna, que, em princípio, é extensiva a todos os públicos e todas as idades, requer programas mais elaborados, cujo custo deve adaptar-se ao número virtual de telespectadores disponível e aos rendimentos publicitários que podem ser aferidos.

\section{Do panorama geral: a Rede Globo de Televisão (RGT)}

Líder absoluta de audiência no país, a Rede Globo de Televisão (RGT) é assistida diariamente por mais de 150 milhões de pessoas, atingindo 98,53\% do território nacional. No ar há cinquenta anos (1965), a emissora, na tentativa, por razões mercadológicas, de se sobrepor às demais grandes cadeias de televisão do país, apropriou-se, pioneiramente, do discurso da qualidade, dedicando-se à implementação e conservação do que se tornou conhecido como o Padrão Globo de Qualidade, uma ideologia geradora de um conjunto rigoroso de regras, implícitas e explícitas, que norteiam suas operações e distinguem sua forma de atuação das práticas de outras concorrentes nacionais (DUARTE, 2013). Em razão dessa decisão estratégica, a RGT passou a dominar a audiência, e, consequentemente, a definir os padrões de qualidade a serem perseguidos pelas demais emissoras, visto que sua produção tornou-se referência, objeto de respeito, admiração e imitação por parte da concorrência.

O modelo de atuação empregado da RGT, que, aliás, vem sendo mantido com pequenas alterações desde 1976, tem como foco os setores comercial e produtivo, fundando-se de um lado na realização de grande parte dos produtos exibidos pela emissora; de outro, na substituição da figura do patrocinador único, responsável pela realização/exibição de determinados programas, pela venda tanto dos espaços comerciais intervalares, abertos no desenrolar das emissões, como, posteriormente, daqueles ocupados com as inserções publicitárias no interior das próprias emissões, o que vem lhe permitindo 
obter maiores lucros e, consequentemente, mais autonomia no desenvolvimento de sua grade de programação.

A grade fixa, tanto na vertical, sequência dos programas no dia, quanto na horizontal, sequência das emissões dos diferentes programas ao longo da semana, vem, ao longo dos anos, preenchendo o horário nobre com duas telenovelas de temática mais leve, encaixadas por telejornais curtos e sintéticos, o jornal local e o Jornal nacional, e uma telenovela de produção mais sofisticada e enredo mais forte, a atual novela das nove. A partir das $22 \mathrm{~h}$, a emissora tradicionalmente exibia uma linha de produtos que, dependendo do dia da semana, comportava filmes, futebol, seriados produzidos por ela mesma, reportagens (Globo Repórter, Profissão Repórter). Todos esses programas eram apresentados com bastante regularidade de horário, exceto nos verões, após as $22 \mathrm{~h}$, quando a programação dessa faixa horária era substituída por minisséries, reprises de filmes e o Big Brother Brasil. A permanência desse padrão tem sido, ao longo da história da RGT, decisiva para a conquista da liderança em termos de audiência.

Mas, como se tem ressaltando em trabalhos anteriores (DUARTE, 2012), o modo de atuação da RGT vem passando por significativas alterações. De um lado, o modelo estrutural adotado pela emissora na realização de seus produtos vem aos poucos se complexificando, devido à decisão estratégica de ocupar também parte do espaço interno dos programas para responder a outros interesses: seu departamento comercial vem sobrecarregando o interior dos textos dos programas com os merchandisings publicitários de toda ordem que interferem, às vezes, grosseiramente, nas tramas narrativas; de outro, alguns setores da empresa vêm investindo pesado na autorreferenciação descarada das produções da própria emissora, na autopromoção de sua imagem e fazer, na divulgação da qualidade e aceitação de seus próprios produtos ou daqueles realizados por outros segmentos das Organizações Globo, na reiteração da competência de seus executivos e elenco permanente.

Além disso, uma mera observação dos conteúdos postos em circulação em sua programação, evidencia de pronto o esforço atual da RGT em construir uma imagem de qualidade também ligada à responsabilidade social, ao compromisso com a democracia e com o pluralismo cultural.

Não bastassem essas transformações ocorridas no interior dos programas, agora é sua grade de programação que vem sofrendo, nos últimos três anos, inúmeras modificações, dentre as quais se destacam, na sequência, as consideradas mais representativas: 
a) alterações significativas no modelo de programação por ela adotado - a RGT, com a sobrecarga e diversidade da programação exibida no final das noites, deixou de observar uma de suas regras básicas: a manutenção de horários fixos para a veiculação dos programas. O Jornal da Globo e o Programa do Jô, por exemplo, são exibidos, a cada dia da semana, em horários diferentes, sempre depois da meianoite;

b) a evidente deliberação de prolongamento do espaço de tempo considerado como horário nobre - a RGT parece determinada a avançar na noite, aumentando o espaço temporal do prime time e, consequentemente, seus lucros comerciais com a exibição de programas bastante qualificados - telenovelas e remakes, seriados diversos e programas de auditório - que avançam noite adentro;

c) o desrespeito e invasão descarada dos horários tradicionalmente reservados à produção local - a RGT vem, sistematicamente, apropriando-se de horários que, por contrato, eram destinados à exibição de programação local, realizada por suas filiadas e afiliadas - esse é o caso de Teledomingo, exibido tradicionalmente aos domingos, depois do Fantástico, e que, em grande parte de 2014 passou a ser veiculado nas madrugadas de segundas-feiras;

d) o expurgo do público infantil - a RGT deixou de exibir programas infantis em sua programação matinal: Sítio do Picapau Amarelo, desenhos, Xuxa, TV Globinho, ICarly, Festival de Desenhos, entre tantos outros, são hoje águas passadas. Atualmente, às vezes, domingos, às $5 \mathrm{~h}$ da manhã, quando há furo na programação, a emissora exibe uma animação, que certamente não tem como foco as crianças que, nesse horário, estão dormindo. É de se perguntar, portanto, onde está esse público, o que mudou no contexto social que os retirou da frente da telinha (jogos?, canais pagos?), ou, ainda, em nome de que interesses a RGT abdicou dessa parcela de telespectadores;

e) a realização de investimentos ainda mais pesados na produção ficcional - a RGT tem investido na produção e oferta de novos seriados, minisséries, mininovelas, remakes, na tentativa escrachada de ocupação também do horário das $23 \mathrm{~h}$ com programas ficcionais. Assim, a exibição de tais produtos tem se intensificado: em certos períodos do ano, às terças e quintas-feiras, depois da novela das nove, são apresentados na sequência não apenas um, mas dois seriados, isso quando não há a exibição de mininovelas, depois das $23 \mathrm{~h}$, de terça a sexta-feira. É de se questionar a 
identidade e caracterização desse novo público alvo visado pela emissora, constituído por aqueles que podem se dar ao luxo de assistir à ficção nesse horário avançado da noite. Certamente ele não é formado por trabalhadores que iniciam sua jornada matinal às $7 \mathrm{~h}$ ou às $8 \mathrm{~h}$.

f) a aposta significativa em remakes de antigos sucessos da emissora - a RGT tem investido na realização de remakes de novelas e de outros tipos de produções que foram sucesso há décadas na emissora. Somente nos últimos três anos, a emissora produziu os seguintes remakes: Saramandaia (56 capítulos), exibida em sua segunda versão, de 24/06/2013 a 27/09/2013, no horário das 23h; Guerra dos Sexos (179 capítulos), exibida, em sua segunda versão, de 01/10/2012 a 24/04/2013, no horário das 19h30min; Gabriela (77 capítulos), exibida, em sua segunda versão, de 18/06/2012 a 26/10/2012, no horário das 23h; O Astro (64 capítulos), exibida, em sua segunda versão, de 12/07/2011 a 28/10/2011, no horário das 23h; 0 Bem Amado (4 capítulos), exibido, em sua segunda versão, de 18/01/2011 a 21/01/2011, no horário das 23h; Ti-ti-ti (209 capítulos), exibida, em sua segunda versão, de 19/07/2010 a 18/03/2011, no horário das 19h30min. E, em 2014, um remake de Rebu. Essa ênfase nas reapresentações parece ao incauto vir na contramão, beirando ao retrocesso, pois, se é verdade que a televisão sempre recorreu a adaptações, referências e apropriações de outros discursos, a exacerbação dessa tendência nos últimos tempos parece falta de opção, ou à falsa ilusão de reedição de um sucesso de audiência. Se é verdade que essas novas versões de programas antigos são uma oportunidade para as novas gerações conhecerem velhas histórias, é bastante difícil fazer com que esses remakes correspondam às expectativas: trata-se de um processo bastante complexo que não se reduz ao mero revestimento desses produtos com novas roupagens, até porque, algumas vezes, esses textos são atualizados para o contexto da última década. É, ao menos, surpreendente, que uma emissora como a RGT - que possui um dos maiores centros de realização ficcional do mundo, o Projac; que conta com núcleos de produção altamente capacitados; e que dispõe de um elenco fixo composto por atores bastante qualificados -, venha investindo tão ostensivamente na realização de remakes, exibidos principalmente em horários avançados da noite;

g) a invasão incondicional da grade pelos programas de auditório - a RGT veiculou, somente nos anos de 2013 e 2014, cerca de doze (12) programas anuais de 
auditório, apresentados em diferentes dias e faixas horárias, e, em princípio, destinados a diferentes públicos, atabalhoando com isso sua grade de programação. Este item será desenvolvido na seção que segue.

\section{Sobre os programas de auditório}

Os programas de auditório, antiga atração do rádio, têm sido um tipo de produto com presença obrigatória no contexto televisual brasileiro: com características e tom, por vezes, bastante popularesco e apelativo, estão presentes nas grades de programação desde o início da atuação da televisão no país. Sua estrutura, originária dos concursos de calouros radiofônicos, foi ganhando, com o passar do tempo, contornos próprios na televisão, como a inclusão de quadros de entrevistas, apresentação de números de dança, atrações musicais e concursos (FERREIRA, 2011).

Alguns elementos constituitivos dos programas de auditório são responsáveis pela exitosa estratégia de comunicabilidade por eles empregados para articular palco e plateia, telespectadores e produto midiático: o que caracteriza os programas de auditório ${ }^{1}$ é a presença obrigatória de um apresentador e da plateia, composta por participantes de origens diversas, que assistem in loco ao programa, interagindo com seu elenco fixo e convidados através de diferentes tipos de manifestações, quer mediante aplausos, vaias, diálogos e outros tipos de expressão, quer se submetendo a provas, games, brincadeiras, entrevistas, quer ainda recebendo, em alguns casos, prêmios pelo ingresso e/ou vitória em competições.

Mas a figura central dos programas de auditório é, sem dúvida, a do apresentador, com funções diversas de condutor, animador, anfitrião, mediador e, por vezes, juiz. É ele quem articula o programa tanto pelo discurso que constrói frente às câmeras, como por sua personalidade e carisma. São atribuídas a ele diversas tarefas, cabendo convocar os participantes, interpelá-los pelo nome; reforçar pela repetição o efeito de diálogo; fazer piadas, brincadeiras; explicar as regras do jogo; divulgar produtos; exibir ancoragens espaciais diversificadas; criar efeitos de participação dos telespectadores, pois o condutor, ao se dirigir diretamente à plateia que assiste ao programa ao vivo, ao se posicionar frente à câmera, interpela diretamente os telespectadores.

\footnotetext{
${ }^{1}$ São famosos, entre outros, na televisão brasileira, o Programa de Gala (1955, TV Rio); o 8 ou 800 (RGT); O céu é o limite (SBT); Calouros em Desfile, Hebe comanda o espetáculo, Com a mão na massa, 0 mundo é das mulheres e Maiôs à beira-mar (SBT); Discoteca do Chacrinha, Buzina do Chacrinha e a Hora do Chacrinha (RGT); Programa Silvio Santos (SBT), etc.
} 
Articulando diferentes gêneros - o factual, o ficcional, o simulacional, o promocional -, os programas de auditório convocam diferentes realidades discursivas, em uma ciranda que relaciona novidade e repetição. As transformações ocorridas ao longo do tempo possibilitaram migrações para o interior das emissões de diferentes subgêneros, complexificando a estrutura dos programas de auditório. Além disso, o avanço tecnológico e a proliferação das estratégias de captação/inserção de textos, advindos de outras mídias, vêm tornando sua estrutura cada vez mais híbrida, pois prevê uma variedade de atrações, apresentadas no decorrer de uma mesma emissão do programa. A dinâmica dos quadros, a estrutura cenográfica do programa, as dançarinas de palco, a participação da plateia, cantando, dançando, tomando parte das brincadeiras, votando, a interação com os telespectadores/internautas, por meio de comentários, votos -, são todos movimentos que auxiliam na composição e êxito dos programas de auditório.

Articulando merchandisings, marketings sociais e diferentes tipos de assistencialismo aliados à exploração de histórias de vida, esses programas convidam à dramatização: põem em cena imagens, acontecimentos, exacerbando sua relevância e/ou gravidade, conferindo destaque ao incomum, ao trágico, com vistas a provocar a emoção da plateia e do telespectador, a causar piedade e compaixão.

Atualmente, pelo menos na RGT, os programas de auditório voltaram à ordem do dia, passando a ocupar imenso espaço em sua grade de programação. Dentre os programas de auditório em exibição pela RGT, nos anos de 2011, 2012, 2013 e 2014, estão:

a) Encontro com Fátima Bernardes (exibido desde 25/06/2012, de segunda a sextafeira, das 10h45min às $12 \mathrm{~h}$ ), comandado por Fátima Bernardes, o programa, em formato arena, discute, a cada emissão, temas do cotidiano brasileiro com os participantes fixos, os convidados especiais, muitos deles artistas da emissora, especialistas e pessoas da plateia, predominantemente constituída por mulheres, contando também com a exibição de reportagens e a apresentação de cantores e/ou grupos musicais. 0 público alvo são mulheres, idosos e aposentados;

b) Programa do Jô (exibido desde 03/04/2000, de segunda a sexta-feira, atualmente sem horário fixo de início, entre 0h30min e 1h30min), comandado por Jô Soares, o programa, em formato palco/plateia, apresenta entrevistas com convidados, muitos deles artistas da emissora, especialistas, cantores, músicos e conta com plateia, que se manifesta através de palmas, gritos, assobios. Seu público alvo são pessoas que 
gostam de temas tratados com um humor mais sofisticado e estão disponíveis durante a madrugada;

c) TV Xuxa (exibido de 04/04/2005 até o final de 2013, todos os sábados, das 14h45min às 16h), comandado por Xuxa Meneghel, o programa, em formato palco/plateia, conta com a participação de júri constituído por artistas da emissora e de candidatos, intercalando a apresentação de cantores/bandas com quadros de concurso musical, relatos de histórias de vida, competições e bate-papos com os convidados famosos. 0 público alvo são aqueles que dispõem desse tempo aos sábados à tarde;

d) Caldeirão do Huck (exibido desde 08/04/2000, todos os sábados, das 16h às 18h), comandado por Luciano Huck, o programa, em formato palco/plateia, conta com a presença de convidados, na maioria artistas da emissora e músicos, participantes e plateia, contendo vários quadros que se alternam de uma emissão a outra, com desafios, nos quais os participantes devem executar determinada prova com vistas à realização de seu grande sonho, a exemplo do Lata Velha, Lar Doce Lar, Agora ou Nunca, além de entrevistas, apresentações musicais e reportagens com temáticas variadas, apresentação de lugares no exterior, etc. 0 público alvo são os telespectadores, classes média/baixa, que ficam em casa sábado à tarde e sentem-se encantados com a possibilidade de a sorte bater em sua porta;

e) Altas Horas (exibido desde 14/10/2000, todos os sábados, das 23h15min às 0h30min), comandado por Serginho Groisman, o programa, em formato arena, conta com convidados, na maioria artistas da emissora e músicos, alternando entrevistas, reportagens, apresentações musicais, além de alguns quadros, como Sexo com Laura Müller, Com Quem Me Pareço, Quinze Segundos de Fama. A plateia, composta majoritariamente por jovens, participa de modo ativo, através de perguntas, protestos, palmas e depoimentos. 0 público alvo do programa são jovens e adultos que curtem música e que estão em casa na madrugada de sábado para domingo;

f) Domingão do Faustão (exibido desde 26/03/1989, todos os domingos, das $17 \mathrm{~h}$ às 20h30min), comandado por Fausto Silva, o programa, em formato palco/plateia, conta com a presença de convidados, na maioria artistas da emissora, intercalando a apresentação de cantores e bandas, com inúmeros quadros apresentados, entrevistas, reportagens, competições, concursos. A plateia, composta por um público heterogêneo e popular, participa de modo ativo através de perguntas, 
protestos, palmas, depoimentos e votos. 0 público alvo do programa é o grupo familiar que normalmente está em casa no final da tarde de domingo;

g) Esquenta! (exibido inicialmente por temporadas desde 02/01/2011, e atualmente fazendo parte da grade fixa aos domingos, das 14h30min às $15 \mathrm{~h} 45 \mathrm{~min}$ ), comandado por Regina Casé, o programa, em formato arena, conta com participantes fixos, além de convidados e plateia, intercalando debates e entrevistas sobre o cotidiano dos brasileiros, principalmente das periferias, com a apresentação de uma diversidade de quadros, voltados especialmente à música brasileira - compositores e cantores. 0 público alvo são os telespectadores que apreciam música nacional, especialmente o samba carioca;

h) Na Moral (exibido por temporadas - 05/07/2012 a 30/08/12, 04/07/2013 a 26/07/2013 e 03/07/2014 a 14/08/2014, às quintas-feiras, das $23 \mathrm{~h} 25$ às 0h20), comandado por Pedro Bial, o programa, em formato arena, conta com a presença de convidados e plateia que debatem temas relacionados ao cenário brasileiro atual sociedade, política, economia, cultura, entre outros -, recorrendo à exibição de reportagens sobre a temática, ao longo da emissão do programa. Os telespectadores têm condições de participar via internet, enviando comentários e dúvidas. 0 público alvo são telespectadores interessados no aprofundamento de determinadas questões, habituados a dormir tarde, e com condições de interagir com o programa via internet;

i) The Voice Brasil (exibidos por temporadas, de 23/09/2012 a 16/12/2012, aos domingos à tarde; de 03/10/2013 a 23/12/2013 e 18/09/2014 a 25/12/2014, às quintas-feiras, das 22h30min à $0 \mathrm{~h} 15 \mathrm{~min}$ ), comandado por Tiago Leifert, o programa, em formato palco/plateia, conta com participantes cantores, um júri composto pelos cantores Cláudia Leite, Lulu Santos, Daniel, Carlinhos Brown e plateia, girando em torno de um concurso anual em busca do melhor cantor do Brasil; apresenta quadros sobre a vida dos cantores participantes, e o concurso no final é decidido pelo voto, via internet, dos telespectadores. 0 público alvo são os telespectadores que apreciam música, em especial os internautas capazes de votar;

j) Amor e Sexo (exibido por temporadas, de 28/08/2009 a 06/11/2009; de 01/02/2011 a 22/03/2011; de 07/07/2011 a 01/09/2011; de 03/11/2011 a 22/12/2011; de 31/01/2012 a 06/03/2012; de 06/09/2012 a 25/10/2012; de 03/10/2013 a 19/12/2013; e de 09/10/2014 a 18/12/2014, às quintas-feiras, das 
23h à 0h), comandado por Fernanda Lima, o programa, em formato arena, conta com a presença de convidados, júri e plateia, que debatem questões envolvendo tipos variados de relacionamentos, com atenção especial aos sexuais. 0 programa mescla entrevistas, reportagens, depoimentos dos convidados (sexólogos, psicólogos, terapeutas) e da plateia, quadros e competições, com a apresentação de uma banda que dita o ritmo das brincadeiras e anima os participantes. 0 público alvo são pessoas, com idade próxima dos 40 anos, interessadas na discussão de questões afetivas e sexuais;

k) Superstar (exibido de 06/04/2014 a 06/07/14, aos domingos, das 23h05min às 0h15min), comandado por Fernanda Lima e tendo Fernanda Paes Leme como responsável pelas redes sociais, o programa, uma franquia do programa israelense Rising star, em formato palco/platéia, conta com um júri composto por Ivete Sangalo, Fábio Júnior e Dinho Ouro Preto, apresenta um concurso de bandas;

l) Video Show (exibido desde 20/03/1983, todos os dias, tendo auditório desde $18 / 11 / 2013$, de segundas a sextas-feiras, das $14 \mathrm{~h}$ às $14 \mathrm{~h} 45 \mathrm{~min}$ ), comandado por Zeca Camargo desde outubro de 2013, é um show de variedades, dedicado a curiosidades de bastidores, entrevistas e brincadeiras com famosos, contando também com quadros com palco, plateia e bandas.

É preciso ressaltar, mais uma vez, que todos esses programas de auditório contam, dentre seus convidados especiais, com atores e profissionais da RGT, que ali estão sob os mais diferentes pretextos. Além disso, o espaço interno dos programas de auditório aparece sempre e impreterivelmente invadido por merchandisings de toda a ordem - publicitários, sociais e autopromocionais.

\section{Apontamentos finais: algumas observações}

Frente a essas alterações bastante significativas na programação da RGT afastamento das crianças da grade; investimento pesado na ocupação de outros horários para apresentação da produção ficcional e remakes; proliferação dos programas de auditório -, é possível levantar algumas suposições ou hipóteses que permitam melhor explicar as razões e sentidos dessas mudanças.

Tudo indica, como bem assinala Montaño (2014), que a grade de programação atual venha tentando substituir um modo de funcionamento já ultrapassado, adequando-se a uma série de transformações em curso, ou seja, substituindo seu consagrado modelo estático por 
outro, bastante mais dinâmico e adequado às formas de consumo da audiovisualidade contemporânea.

Mas o que torna instigante o exame das modificações operadas na grade de programação é exatamente o fato de que essas alterações apontam diferentes sentidos: se atualmente o vídeo e a televisão na internet podem prescindir da televisão, ela, não obstante, não parece disposta a abdicar de seu espaço. Ao contrário, se opera transformações/adaptações, essas se devem exatamente à sua firme intenção de continuar ocupando o espaço privilegiado, que sempre deteve, de mídia de maior circulação e consumo.

A forma tradicional de organização da programação televisual era destinada à assistência da televisão no âmbito familiar; adequava o horário de exibição dos programas à rotina doméstica. Hoje, não obstante, as emissoras não direcionam sua programação apenas a determinadas fatias do público e aos seus supostos hábitos cotidianos. Assim, embora ainda reiterem sua programação, estruturem os programas prevendo breaks comerciais e planejem interrupções que deixem os telespectadores desejosos de acompanhar as próximas emissões, as empresas televisuais parecem bem conscientes das operações realizadas pelos telespectadores em outras plataformas: afinal, vive-se na era da internet, das redes sociais, dos dispositivos móveis que, sem dúvida, possibilitam outras formas de consumo de seus produtos.

Cabem, portanto, inúmeros questionamentos sobre a permanência de uma fórmula de estruturação da programação televisual cujo caráter produtivo e econômico parece esgotado, correndo perigo de extinção. 0 próprio investimento maciço no cast - composto por atores, colunistas, correspondentes, artistas competentes e famosos - começa a parecer inviável até mesmo para o enorme monopólio representado pela Rede Globo de Televisão.

No que concerne ao público infantil, se as crianças parecem ter sido deixadas de lado, sendo seus interesses ignorados pela programação, essa abdicação é aparente: as crianças classe média têm hoje acesso a inúmeros canais pagos, com programação inteiramente direcionada a elas. Além disso, muitas delas vêm sendo iniciadas, bastante cedo, nos meios eletrônicos, nos quais também podem assistir a essa programação. Por outro lado, a maioria das mães atualmente trabalha fora e as babás são hoje bastante mais caras e raras; as crianças entram mais cedo e ficam mais tempo em maternais, pré-escolas, jardins de infância, ou seja, têm menos tempo para assistir à televisão. Mais ainda, elas não se constituem no público consumidor por excelência de determinados tipos de produto, o que 
reduz as apostas publicitárias feitas por certas empresas nos espaços destinados aos programas infantis, o que justificaria o direcionamento do horário matinal às mulheres, aos idosos e aos aposentados, que assim deve render mais.

Fica evidente que a RGT decidiu investir no horário do final de noite, e tornar a faixa que se inicia às $23 \mathrm{~h}$ mais rentável: talvez ela seja aquela em que o público, já deitado, possa consumir televisão da forma tradicional. Mas como, para tanto, a emissora precise cativar os telespectadores e garantir a audiência, ela vem testando suas preferências com a oferta de diferentes produtos, visando melhor aferir sua receptividade e acertar suas ofertas.

Já o investimento nos programas de auditório parece ser uma tentativa de resposta da televisão a esse novo cenário: a forma de estruturação desses produtos possibilita com que os consumidores possam assisti-los enquanto zapeiam na fila do banco em seus smartphones ou depois no YouTube, em busca do que lhes interessa.

Além disso, os programas de auditório sempre foram palco principal da disputa pela audiência travada pelas emissoras. Tanto isso é verdade que apresentadores como Fausto Silva, Serginho Groisman, Angélica e até mesmo Jô Soares, oriundos de outras redes de televisão, tiveram seu passe comprado pela RGT. A esse respeito, lembra-se que: dentre os programas de auditório em exibição, dois deles correspondem à venda de formatos por produtos internacionais - The Voice e Superstar.

Ora, a aposta da RGT nos programas de auditório exibidos em diferentes horários e direcionados a distintos públicos, que pode parecer um retrocesso, justifica-se, pelos aspectos econômicos envolvidos, visto que esse tipo de produção é bastante econômica - os participantes são tanto atores sociais e artistas que desejam promover o seu fazer, como os profissionais que fazem parte do casting da emissora que vêm autopromover os seus trabalhos.

A permanente disputa pela audiência entre as emissoras, relacionada às verbas publicitárias, encontra nesse tipo de produto uma solução bastante sedutora de oferta. Os programas de auditório parecem ser hoje um espaço privilegiado de veiculação para toda forma de promoção - do merchandising comercial às diferentes formas de autopromoção empregadas por uma emissora. Assim, a decisão de colocar no ar mais programas de auditório está intimamente relacionada aos aspectos comerciais e econômicos, à possibilidade de patrocinadores: as inserções publicitárias (merchandisings) correspondem a uma das principais fontes de renda das emissoras, sustentando com isso a realização de 
programas mais sofisticados e qualificados tecnologicamente, bem como a aferição de lucros.

E os programas de auditório, além dessas vantagens econômicas e comerciais, são um espaço privilegiado para a autopromoção da própria emissora: para o lançamento de produtos no mercado televisual; para a divulgação de livros, filmes e CDs, produzidos pelas Organizações Globo, entre outros tantos. Além disso, como se pode assinalar, tratam-se de produções de baixo custo, que se utilizam da prata da casa e podem ser consumidas em diferentes plataformas.

\section{Referências}

DUARTE, Elizabeth Bastos. Televisão: ensaios metodológicos. Porto Alegre: Sulina, 2004. Col. Estudos sobre o audiovisual.

DUARTE, Elizabeth Bastos; CURVELLO, Vanessa (colaboração). Ficção televisual: distintas formas de estruturação seriada. Anais do XXXI Congresso Brasileiro de Ciências da Comunicação - Intercom. Natal: UFRN, 2008 (eletrônico).

DUARTE, Elizabeth Bastos. Televisão: novas modalidades de contar as narrativas.

Contemporânea. Salvador, v. 10, Universidade Federal da Bahia. 2012. p. 324-339.

DUARTE, Elizabeth Bastos. Como caracterizar qualidade em relação à produção da Rede Globo de Televisão? In: PEREIRA, Cárlida Emerim Jacinto, org. Estudos em jornalismo e mídia. Florianópolis, v. 10, v. 2, Universidade Federal de Santa Catarina, jul./dez. 2013. p. 326-339.

FERREIRA, Renata Claudia Martins. Sucesso no rádio e na televisão, o programa de auditório não morre: uma análise do Programa Carlos Santos na TV. Belém: Programa de Pós-Graduação em Comunicação, Linguagens e Cultura, Universidade da Amazônia, 2011 (Dissertação de Mestrado). Disponível em: <http://www.unama.br/novoportal/ensino/mestrado/programas/comunicacao/attachme nts/article/110/Dissertação\%20Renata\%20Claudia\%20Martins\%20Ferreira.PDF>. Acessado em: 28.10.2013.

FONTANILLE, Jacques. Semiótica do discurso. Contexto: 2007.

JOST, François. Introduction à l'analyse de la télévision. Paris: Ellipses, 1999.

JOST, François. Compreender a televisão. trad. Elizabeth Bastos Duarte, Maria Lília Dias de Castro, Vanessa Curvello. Porto Alegre: Sulina, 2010. Col. Estudos sobre o audiovisual.

KILPP, Suzana. Quadros de entrevista em programas de auditório: alternativa para análise da TV no Brasil. Website Suzana Kilpp. Disponível em:

<http://www.suzanakilpp.com.br/artigos/Quadros_de_Entrevista_em_Programas_de_Audit orio.pdf>. Acessado em: 23.10.2013. 
MONTAÑO, Sonia. Relato do trabalho Reflexões: os sentidos sociais da programação. In: XXIII Encontro anual da Associação Nacional dos Programas de Pós-Graduação em Comunicação -Compós (GT Estudos de Televisão). Belém: Compós, GT Estudos de Televisão, 2014.

SOUSA, Sílvia Maria de. Apontamentos sobre o gênero programa de auditório. RUA Revista Universitária do Audiovisual (on line), 2009. Disponível em: <http://www.rua.ufscar.br/site/?p=2502>. Acessado em: 25.10.2013.

TORRES, Carmen Ligia Cesar Lopes. Programas de auditório: um gênero mostrando a resistência da expressão popular nos meios de comunicação de massa. Trabalho apresentado no IV Encontro dos Núcleos de Pesquisa da Intercom. 2004. Disponível em: <http://www.portcom.intercom.org.br/pdfs/38987853589686536615516015929805656 497.pdf>. Acessado em: 23.10.2013.

\title{
Reflections: social meanings of the schedule
}

\begin{abstract}
This paper aims to develop a reflection about the operation, logics and functions governing the establishment of the main channels time slots, examining with dedicated attention the Rede Globo programmation adjustments, with the purpose to call into hypothesis to be confirmed in a posterior research, which enable to understand the meanings and the reasons that guide the current adjustments. In this perspective, seeks to analyse the investments made by the issuer in the fictional production in remakes and, mainly, in the Auditorium, since currently the RGT puts on the air, weekly, more than 12 programs, connected to this televisual subgenre. The final notes seeking to submit justifications for those changes
\end{abstract}

\section{Keywords}

Time slot. Establishment principles. Meaning of the adjustment.

Recebido em 13/01/2015

Aceito em 06/07/2015 